\title{
An empirical ethical analysis of community treatment orders (CTOs) within mental health services in England
}

Michael Dunn, Krysia Canvin, Jorun Rugkasa, Julia Sinclair and Tom Burns

In print: Clinical Ethics, 11(4): 130-139

\begin{abstract}
Community treatment orders (CTOs) are a legal mechanism to extend powers of compulsion into outpatient mental health settings in certain circumstances. Previous ethical analyses of these powers have explored a perceived tension between a duty to respect personal freedoms and autonomy and a duty to ensure that patients with the most complex needs are able to receive beneficial care and support that maximises their welfare in the longerterm. This empirical ethics paper presents an analysis of 75 interviews with psychiatrists, patients and family carers to show how these ethical considerations map onto the different ways that CTOs are used and experienced in practice. A complex and nuanced account of how the requirements to respect patients' autonomy, to respect patients' liberty, and to act beneficently should be interpreted in order to make judgements about the ethics of CTOs is presented. The paper argues that, due to such complexity, no general ethical justification for CTOs can be provided, but that a justification on the basis of the promotion of patients' autonomy could provide an ethical reason for community mental health practitioners to make use of a CTO in some limited circumstances.
\end{abstract}

\section{Keywords}

Community treatment orders; CTOs; mental health; psychiatry; psychiatric ethics 


\section{Introduction}

In recent years, research in psychiatric ethics has begun to shift its attention away from hospital care and onto those services provided for patients in the community. This shift has been characterised by a refocusing of inquiry onto the ethical issues arising in the long-term and multi-disciplinary health and social support of patients, which itself has tracked an evolving regulatory landscape that has seen the extension of legal powers of treatment into outpatient settings. Across a number of jurisdictions, community treatment orders (CTOs) ${ }^{1}$ have been introduced as a way of governing the legally mandated provision of care and treatment to those with enduring mental disorders and high levels of need who meet the stipulated criteria.

In England and Wales, CTOs were introduced in the revisions made to the Mental Health Act in 2007 as a long-term approach to the provision of legally-supervised care in the community (Mental Health Act 2007, s.17A-G). An order should be issued under the CTO regime prior to the patient being discharged from hospital, and this order permits the recall of the patient to hospital in two circumstances. First, when the patient requires treatment in hospital and in the absence of recall there would be a risk of harm to self or others, or, second, when the patient does not comply with one of two mandatory conditions. These involve requiring the patient to make him/herself available for assessment, first, when an independent doctor is assessing the appropriateness of the treatment at an early stage of the СТO and, second, when renewal of the СТО is considered. 
Additionally, the СTO regime allows a range of discretionary conditions to be incorporated into the order. These conditions are tailored to the individual patient and designed to ensure that medical treatment continues, that the patient's health or safety is safeguarded, and/or that other people are protected. The most frequently stipulated conditions are taking prescribed medication and remaining in contact with the mental health team (Care Quality Commission, 2013), but other conditions might extend to the use of a curfew, limitations placed on where the person resides, abstinence from drugs or alcohol, and restrictions being placed on particular places that the patient is permitted to visit. Whilst a СTO can involve imposing significant limitations on a patient's daily routine and activities, the CTO does not permit the patient to be forcibly treated with medication outside a hospital setting.

Ethicists studying CTOs have largely been critical of what has been taken to be a new paternalistic approach to the delivery of community-based mental health services. Instigating involuntary outpatient treatment into patients' care regimens outside of hospital has been argued to constitute an unjustified restriction of patients' personal freedoms and autonomy, undermining the principles of respect for liberty and self-determination (LawtonSmith, 2008; Munetz et al., 2003; Snow and Austin, 2009). Progressing beyond the deployment of catch-all normative concepts like 'coercion', these ethical arguments have been accompanied by a more general recognition of, and concern about, the use of a range of pressures to influence patients' adherence to treatment within community mental health settings (Dunn et al., 2012). 
In response to these principle-led attacks on the justification of CTOs, other commentators have offered spirited defences of the new legal powers by highlighting the difficult realities of the lives of those patients who have severe illnesses that undermine treatment adherence and frequently require re-admission to hospital. Established to support these socalled 'revolving door' patients in ways that could secure the longer-term positive outcomes associated with continued treatment and prompt intervention in the face of crisis, CTOs have been claimed to be liberty-enhancing and potentially beneficial to those in receipt of them (Dale, 2010; Dawson and Burns, 2008).

Whilst the ethical discussion has begun to take seriously the realities of the treatment settings within which CTOs are used, the academic psychiatric literature continues to scrutinise whether the ethical considerations identified can be balanced in such a way as to defend the use of CTO regimes in different jurisdictions. Moreover, little is known about how these considerations translate into practice, given the complex and varied mental health and social support needs of the patients who will be subject to these powers. The empirical studies that have explored the experiences of practitioners and patients have highlighted positive and negative views about the use of CTOs in practice (Gibbs et al., 2005; Light et al., 2014; O’Reilly et al., 2006; Stroud et al., in press), but the authors of these studies have not sought to explicate their findings in ways that directly address the ethical questions that concern the use of this new legal power.

In this study, the aim was to connect the real-world experiences and attitudes of patients, practitioners and family carers in order to determine how the relevant ethical considerations identified above should underpin practical judgements about whether CTOs 
are ethically justified as a component of patient care. This empirical ethics analysis of the experiences and attitudes towards the use of CTOs formed part of a larger empirical project investigating this new legal power, employing both clinical trial and qualitative research methods (Burns et al. 2013; Canvin et al. 2014). The qualitative research component of this study aimed to illuminate patients', carers' and practitioners' experiences of CTOs, and to inform an empirically grounded ethical analysis of CTOs, in light of the broader evidence base that emerged about the effectiveness of CTOs from the clinical effectiveness trial.

This process of data collection and analysis reflects a well-recognised methodological tradition in the empirical ethics literature that seeks to use qualitative data to translate wellestablished ethical principles for medical practice into specific ethical judgements about the real-world issues that arise in particular practice settings (e.g. Kon, 2009; Solomon, 2005).Whilst this study concerns practice settings in England, the arguments invoke general ethical considerations that are likely to be applicable to other jurisdictions within which CTOs form part of mental health service delivery.

\section{Methods}

Grounded Theory methodology underpinned the qualitative study design (Strauss \& Corbin 1990, Charmaz 2006), and research ethics approval was sought and obtained from the Staffordshire National Research Ethics Service (NRES) Research Ethics Committee (Reference number 08/H1204/131). Purposive samples of psychiatrists, patients and family carers were sought with a view to obtaining a maximum variation of characteristics in each group (Patton 1990). The patient sample was recruited from the pool of participants from the 
clinical trial, some psychiatrists were recruited from amongst those who had been approached to identify patients for the trial (with others being recruited via NHS trusts, and family carers were recruited via NHS trusts and existing carer organisations. We report on in-depth interviews conducted with 25 consultant psychiatrists, 26 patients and 24 family carers (including 3 couples). The characteristics of the participants in the study are provided in Table 1. In the interviews, participants were invited to describe their experiences of the CTO. The interviewer (KC, JR, or a research assistant) probed participants' views about the positive and negative aspects of the CTO, and encouraged reflection upon differences between the new and previous regimes, as well as inpatient and outpatient care. Particular attention was paid to potential ethical considerations.

INSERT TABLE 1 HERE

All of the interview transcripts were coded (by KC or JR) using the constant-comparative method (Glaser 1965) for the main part of the qualitative study. A focused thematic reanalysis of the qualitative data was undertaken for the ethical component in order to highlight ethical dimensions explicitly. $\mathrm{KC}$ and JR identified relevant codes from the initial analysis, including 'impact of CTO', 'patient/carer/psychiatrist values', and 'future goals' and trawled through the transcripts for additional ethical dimensions that might have been overlooked in the original analysis. The re-analysis of the data involved MD and $\mathrm{KC}$ re-coding and re-categorising these data excerpts according to the three ethical values of 'benefit', 'autonomy' and 'liberty', concerning individual patients, that had been identified in the literature as the considerations relevant to making ethical judgements about the use of CTOs. 
Drawing directly on these previous analyses, the theme of benefit was interpreted as an outcome-orientated consideration that revealed how, and in what ways, a patient was judged to be better or worse off through the use of a CTO. The theme of autonomy was interpreted in terms of the relationship between the patient's ability to pursue a life of value to her and his/her experience of being subject to a CTO. The theme of liberty was interpreted by considering the extent to which patients' freedoms of action were restricted by the use of CTOs. In contrast to the themes of benefit and autonomy - which necessarily include reference to accounts of the individual patient's well-being and personal values and therefore have a subjective component - freedom was taken to be an objectively determined characteristic of the care regime provided under a CTO. Therefore, in those instances where a subjective account of patients' experiences of being more or less free under a CTO were given, these accounts were classed under the theme of benefit (if they were explicated in terms of a positive or negative outcome), or the theme of autonomy (if they were explicated in terms of the patient's ability or inability to make decisions in line with her values). Most of the emphasis of the analysis focuses on considerations relating to benefit and autonomy, therefore, but it is important to recognise that all three themes were identified frequently within this process of data re-analysis.

\section{Results}

The analysis of the data revealed the complex ways in which the ethical considerations of benefit, autonomy and liberty are perceived to play out in the context of individual patient 
care. In all cases, there was evidence both in support, and against, the use of CTOs in light of all three ethical considerations.

\section{$\underline{\text { Patient benefit }}$}

Empirical data from randomised controlled trials of CTOs reveal that this form of treatment fails to reduce readmission to hospital when compared to voluntary outpatient care (Burns et al., 2013; Swartz et al., 1999). Moreover, the clinical trial of CTOs reported in Burns et al (ibid) within which this study is situated concluded that no wider clinical or social benefits, including quality of life or the perceived coerciveness of services, accrued to patients on CTOs when contrasted with those in the control arm. Also, no subgroup of patients benefited more than others (Rugkåsa et al., 2014). In terms of the medical and personal outcome measures adopted in these studies, therefore, there looks to be no benefit for patients from the use of CTOs. However, the qualitative data revealed that a number of those interviewed talked about benefits that could accrue from a patient being placed on a CTO. It is necessary, therefore, to consider the extent to which these personal reports of benefit, articulated by some respondents, might account for positive outcomes that have not been captured in the clinical trial.

Some family carers stressed the speed of response that could be instigated under a CTO as supporting positive outcomes for the patient even if that patient was recalled to hospital: 
“...chiefly it's the speed with which he's dealt with which prevents all this deterioration and building up of bills and filth and ends up in criminal behaviour. I mean that is all saved 'cos they take him in as soon as he stops co-operating" (Carer 2, parent)

This was a view endorsed by some psychiatrists who saw benefits accruing to a patient when recall took place, minimising the decline in a patient's distress and reducing the time required in hospital:

"their difficulty with this man is what to do when he becomes unwell because he just starts moving so fast that organising a Mental Health Act assessment, the logistics of getting two doctors and [a social worker] and him and the police all in one place is so difficult that there's a delay of some days before, between the time they decide he has to come back and where they actually can go through the mechanics of getting him in... And during that delay there is a lot of risk to himself, he deteriorates and that probably costs him some weeks in hospital later on and she said actually if we could just recall him then it would be much better." (Consultant psychiatrist 8 , inpatient)

The importance of being able to get appropriate treatment more quickly than as a voluntary outpatient was also seen by patients as a positive outcome of receiving care under a CTO:

"That is another important point, when I get ill and I'm under the [CTO], I get admitted to hospital quicker than when I'm alone like now, so I save time and I catch up with my illness straightaway and quickly. With myself, not under the [СТО], I will have to see a doctor then the doctor will see another doctor and then they will decide to get me into 
the hospital and then they will send the police. That procedure, nobody likes that procedure." (Patient 3, CMHT, CTO ended)

Despite the speed of readmission being emphasised as a positive feature of patient care under (some) CTO orders, it should be recognised here that it is not rapid readmission itself that constitutes a benefit to patients. Rather, it is the positive health, social and/or personal outcomes that can accrue for a patient in these circumstances. The evidence from the clinical trial reveals that such outcomes do not result from the use of a CTO, at least in the one year time frame within which this study was conducted. Moreover, it is unclear from these interviews whether it is the instigation of a CTO regime that leads to the increased speed of readmission in some cases, or other factors relating to, for example, the efficiency and working patterns of the mental health practitioners involved.

In other interviews, patients emphasised the possibility that CTOs could provide a 'window of opportunity' to maintain their stability in the longer-term by allowing them to establish a new collaborative relationship with the community team. Two psychiatrists suggested that CTOs could improve patients' engagement with services because of the requirement for the patient to agree to the original care plan set in place to govern the use of the CTO. Where the CTO made longer-term stability possible, the legal regime of care management under a СTO was seen by patients as being crucial:

"The thing is when I was unwell I'd function and I'd do the groceries and make the dinner and stuff but l'd be drinking and making up all this stuff in my head and I'm not doing that now. I'm well and I'm stable but I think CTO just because it is threat, threat 
is the wrong word but it's the safeguard, it's the safeguard that if I was to think of going on a bender I just wouldn't because I wouldn't want to jeopardise all this work that I've put into being well again" (Patient 10, CMHT, CTO ongoing)

Whilst this patient identifies that the safeguards associated with her СTO have led to increased stability, again the broader empirical evidence demonstrates that such stability does not materialise for patients (Burns et al., 2013; Rugkåsa, Dawson and Burns, 2014; Maughan et al, 2014). Indeed, evidence from other psychiatrists, patients and family carers reflected concerns that patients were no better off under a СTO when patient benefit was conceptualised more objectively. The difficulty in accessing treatment was highlighted as a particular concern by some:

"The point is a СTO, the most important thing is that they can access treatment, and I don't think; well [patient's name] definitely couldn't access the treatment. The following weekend which was the; cos there's no out of hours service. After 5 o'clock that's it. And the home treatment team you almost have to book them." (Carer 9, parent)

A second concern expressed was that the process of placing a patient on a CTO can ossify care planning, preventing an individual's broader needs being met and undermining a dynamic process of reviewing changes in the services required:

"My disappointment with the Community Treatment Order is that... it keeps [patient's name] quiet. It keeps him very under the weather. I feel in a way that it; if only the 
Community Treatment Order was not just a medical model... if there was a social side going along with it then it would be useful, but I think it just simply holds a situation. OK [patient's name] doesn't become psychotic because of the medication and I know he'd get taken in very quickly if he did stop medicating but it doesn't do anything for recovery or a plan forward. I think it simply contains him, here." (Carer 13, parent)

Whilst the legal powers are different, evidence reported from research conducted in response to the introduction of CTOs in New York State suggests that the experiences expressed by this carer are not uncommon. In that study, the data indicated that the intensive support required to meet the broad personal and social needs of some patients subject to CTOs does not materialise (Steadman et al., 2001). This evidence connects to the concerns raised by patient advocacy groups in the legal reform process in England and Wales. These groups identified the risk that the CTO regime could legitimate the withdrawal of support to these patients on the grounds that their interests were safeguarded by narrow medical treatment-orientated care.

The overall picture in respondents' personal accounts of outcomes resulting from the use of CTOs is mixed, with a range of positive and negative outcomes described. It is also important to recognise that, other than the points made by respondents about the new opportunity for stability for some patients, the interview data regarding outcomes related to claims about how the mental health service was functioning when CTOs were being used, rather than describing the use of CTOs themselves. Little evidence came to light to suggest that the other benefits about personal and social support identified could not have accrued independently of the CTO, if the service was appropriately responsive to patients' needs. 


\section{$\underline{\text { Patient autonomy }}$}

Whilst previous ethical analyses have emphasised that imposing a СTO on a patient who has the capacity to refuse treatment fails to respect patients' autonomy, the restriction of choice in the act of being placed on a CTO was only spontaneously identified as a concern by about half of the patients. Otherwise, the patients interviewed focused their attention on the positive and negative impacts of CTOs on their self-identity, and their ability to modify their life plan in order to act in line with their own values.

One view expressed was that the clarity of knowing how a service would respond if patients they were to act in certain ways was important for these patients, and that this opportunity was not available to them when on short-term leave from hospital:

"I suppose potentially I think CTOs could be seen as being the better of the two from the patient's perspective because at least the conditions are clear and sort of it's not, whereas in Section 17 leave it can you know, it can just be used completely in a coercive way because you're not really sort of setting out what you want, you're saying, you're still under the section" (Consultant psychiatrist 14, CMHT)

This insight was seen as important to patients as well, not just because of the benefit that accrued from understanding where they stood, but in that it provided a route back to a normal life: 
"I feel very, very well, very confident to take steps back to a normal life. I go and see my kids every time - I am separated from the mother who lives in the same house as them, but I visit them like anytime, it's open. I am searching for a job at the moment, I claimed - what is it called - I applied for chances with volunteer organisations, I filled the forms and gave it to them, just to fill my time and to give me the idea of the work environment and having people around you and stuff and getting used to normal people and things" (Patient 3, CMHT, CTO ended)

Again, this suggests that instigating a new legal regime provided a 'window of opportunity' for a patient to evaluate what was of importance to her, and to take active steps to achieve these goals. Interestingly, one patient accounted for this transition in terms of how a legal regime in which she was expected to fulfil certain tasks directly associated with her illness freed her from the constraints that she had placed on herself:

“I'm not under pressure. I'm an entirely free agent. I've got a little area on top of my writing bureau; I've got all my things set out and I know what time, exactly what time I take [medication] and the quantity, how many and yeah I've got a little; it's like a little altar it is to my medication and these little pots." (Patient 32, Forensic, CTO ongoing)

For other patients, however, CTOs were viewed as infantilising, placing them under a regime of supervision that held them back from pursuing options in their lives, rather than enabling them to pursue valuable activities. The following patient illustrates this by commenting on her experiences having been discharged from a CTO: 
"I feel that I'm a free man again you know. I don't need to tell, to let them know of everything I want to do. I've got a bit of privacy. I'm a grown man and I should be able to look after myself." (Patient 2, CMHT, CTO ended)

From the perspective of many family carers, a CTO was viewed as 'containment'; a way of managing the patient in the community that was not associated with the requisite supports that the patient needed to become independent and to act autonomously in their lives:

"It would be a lot better if the team were active and found something for this intelligent man to do. You know he just sits doing crosswords from the newspaper and that's about it now. You know, he's becoming more and more isolated and more and more withdrawn. I think the CTOs just contain him." (Carer 13, parent)

The lack of support that accompanied a CTO was also raised by a patient, who equated the imposition of this legal power with the limited opportunity to embark on a range of activities in his life:

"You know it's imprisoning them, it's imprisoning them in a system that can only just maintain some sort of degree or normality you know. They think they can preserve some degree of normality whereas people can if given the opportunity of being allowed off of a CTO for six months..." (Patient 17, СMHT, СTO ended)

There looks to be qualified support for CTOs in light of the obligation to promote a patient's autonomy, even if it is correct to observe that the original decision to place a competent 
patient on a CTO fails to respect that patient's autonomy. However, it is again important to note that the majority of the accounts of patients' abilities to act autonomously within the community setting hinge on whether appropriate personal and social support is provided within the mental health service, rather than being determined by the use of the legal power itself. It is only for those small numbers of patients who view the legal regime of the CTO as liberating them from the difficulties of managing their illness to focus on other life goals that mandated community treatment looks to be justified from the standpoint of autonomy.

\section{Patient liberty}

Given that clinicians are able to determine the specific content of the discretionary conditions of the order, it is unsurprising that the impact that CTOs can have on patients' liberty has been identified as an ethical concern. However, it is also clear that CTOs are less liberty-restricting than the use of compulsory powers of detention and treatment within inpatient settings. This position was endorsed widely by psychiatrists, patients and family carers, all of whom recognised that patients' freedoms were better protected by CTOs when contrasted with inpatient care.

The evidence from the clinical trial reported by Burns et al (2013) also reveals important differences between the degree of freedom enjoyed by patients under CTOs when contrasted to those in the control arm. Those randomised onto the CTO arm of the trial were subject to this legal power for the subsequent 182 days (median) against 8 days for those in the control arm who left hospital via section 17 leave of absense. This pattern was 
repeated in the year's follow-up, where those in the СТO arm were subject to legal powers of compulsion for a total of 255 days against 102 days for controls. Given that the CTO regime allows a range of conditions to be placed on what patients are able and not able to do, these figures clearly suggest that those placed upon CTOs have their liberties restricted, in more substantive ways and for longer periods of times, than other patients.

Examination of the interview data reveals additional insights into how patients experience freedom under a CTO compared with their experiences of outpatient care more generally. Perhaps surprisingly, the CTO regime were seen by a number of patients as being no more restrictive than being a voluntary outpatient. This observation was explained in terms of the ways in which patients and carers saw community services supporting those with severe and enduring mental disorders. Three patients expressed concerns that, as people eligible to receive mental health services, their freedoms were constantly at risk on the grounds that they were caught up in a system that demanded compliance from them. Whilst, in legal terms, patients enjoyed greater freedoms when not subject to such powers, the same patients identified that they could not easily differentiate between the restrictions imposed by the СТO and their experience of being treated as a voluntary outpatient. This is illustrated by the following patient's account of re-hospitalisation:

"I mean I just want to be free from the mental health services and get on with my life. Go to college and I'm able to do that but I feel like I'm not being allowed to because all it takes is for you to go unwell once like with drugs and be taken to hospital and then they're all talking about, oh he's got schizophrenia again..." (Patient 1, CMHT, CTO ongoing) 
Importantly, however, the implications of such experiences for ethical considerations of liberty need to be reviewed carefully. Whilst this patient might feel that her liberty is being restricted when receiving community mental health care, it is incorrect that her liberty is restricted - as a matter of fact - when she is not subject to legal powers in the community (though, of course, how she exercises her freedom might lead to the imposition of legal powers in the future). The concerns she raises are better diagnosed in terms of the other ethical considerations identified above, such as personal autonomy. Here, her autonomy might fail to be respected within a service that does not support the person to pursue her own life choices adequately, quite independently of whether that patient is being treated under a СТO.

\section{Discussion}

This study has shown how ethical considerations concerning the use of legal powers in community mental health care map onto the different ways that CTOs are used and experienced in practice. A complex and nuanced account of how the ethical principles of respecting patients' autonomy, respecting patients' liberty, and acting beneficently should be interpreted in order to make judgements about the ethical justification of CTOs has emerged.

Previous ethical analyses have pitched this ethical debate largely as a conflict between patient benefits, on the one hand, and liberty and autonomy, on the other, with the implications that this is a debate to be settled one way or the other. However, the varied 
range of experiences documented here suggests that ethical duties can pull in different directions, depending on the individual patient's circumstances. The ethical picture is not as clear, nor as binary, as Lawton-Smith (2008), Munetz et al. (2003), and Snow and Austin (2009) have suggested.

\section{No general ethical justification for CTOS}

One conclusion that does follow from the analysis presented, however, is that no general ethical justification for the legal framework of the CTO can be provided. The reason for drawing this conclusion emerges from a cursory review of how the relevant ethical considerations identified should be interpreted in practice.

CTOs are not the least restrictive alternative when it comes to providing care within community mental health services, though they were widely interpreted as being less restrictive than the use of legal powers of detention in hospital. The conditions that clinicians can place on patients' care regime means that these clinicians must have good ethical reasons for using CTOs over less restrictive ways of supporting patients in the community. If such reasons are not available, CTOs cannot be justified.

Whilst our analysis indicates that some patients, carers and psychiatrists talk about different ways in which patients can benefit from the use of CTOs, it must be recognised that there is no RCT-level evidence that these benefits actually result in improved outcomes for patients. It is not possible therefore to argue that CTOs can be justified from these accounts of benefit - medical, social or personal - that are seen to accrue for some patients for whom 
CTOs are used. In other situations, clear accounts of difficulties or specific harms that patients face under the CTO regime are described.

When considering whether the СTO regime functions to respect patients' autonomy, there is a stronger ethical case to be made that CTOs can, for some patients at least, promote selfdetermination. A number of respondents clearly viewed the imposition of a communitybased legal power as aiding patients in managing their illnesses in ways that enable them take control of their lives and to engage in new activities. Equally, for other patients the evidence suggests that other patients are constrained in their ability to exercise their autonomy in similar circumstances.

\section{Promoting patients' autonomy: a limited justification for the use of CTOs?}

How the ethical argument from autonomy is developed here depends on resolving a practical and conceptual tension between respecting a patient's autonomy and promoting that patient's autonomy. Whilst this tension has been examined to some degree within psychiatric ethics (Liégeois and van Audenhove, 2005), and applied to discussions about mental health practice in light of interventions such as advance mental health directives ${ }^{2}$ (Brock, 1993; Savulescu and Dickenson, 1998; Srebnik and La Fond, 1999), it is not an issue that has been discussed in previous ethical analysis of CTOs. Interview respondents prioritised the promotion of autonomy over mere respect for autonomy when thinking about the ethical legitimacy of CTOs. This position is understandable; given the long-term nature of community-based mental health services, it should be seen as entirely appropriate to foster a person's self-development and support his/her life projects into the future, 
rather than treating that person's values and abilities as static. By way of caution, however, the recent evidence from a RCT of advance directives for mental health suggesting that patient autonomy is not promoted through the use of such interventions (Thornicroft et al., 2013) implies that it is also important to look very closely at whether autonomous choice would indeed be fostered through the use of CTOs in any given clinical situation.

There are two additional difficulties in drawing on an ethical requirement to promote a patient's autonomy to provide an ethical justification for the use of CTOs. The first difficulty is epistemic. Whilst it may be correct that, in some cases, patients' abilities to better pursue choices and activities in line with their own values will be enhanced by invoking a CTO, it will be difficult - if not impossible - for community mental health teams to know whether patient autonomy will be promoted in any given case. Even if there are a small number of situations in which CTOs ought to be used to support the delivery of empowering and person-centred care, it is far from clear whether care providers will be able to identify, in advance, when such situations have arisen.

The second difficulty in mounting an autonomy-based defence of CTOs is that our analysis has revealed that it is challenging to differentiate features associated with the use of a CTO from features of the broader care environment in which this power is invoked. As such, making an ethical judgement about the use of CTOs cannot be separated from the broader ethical requirement that practitioners have to tailor the delivery of care and support services in ways that promote patients' autonomy. The majority of concerns highlighted in the interviews concerned perceived failings in how interventions provided to patients are used to support their care and treatment, rather than constituting evidence that CTOs by 
themselves are harmful or disrespectful of patients' autonomy. Equally, the benefits that respondents felt emerged through the use of CTOs were commonly presented as being contingent on the availability and appropriateness of other interventions designed to provide personal and social support to patients in receipt of care in the community features that are independent of these legal powers in a number of jurisdictions.

If patients' autonomy can be promoted through the more optimal provision of multidisciplinary forms of personal and social support within community services, rather than through the use of CTOs, this is to be preferred as these multidisciplinary interventions do not impose comparable restrictions on patients' freedoms. There is clearly much more to say about the practical and ethical aspects of delivering good care to patients with complex needs within community mental health services. But notwithstanding this observation, this analysis does suggest that it is indeed possible that, in some situations, a CTO might be judged by the clinical team to be a valuable or indeed necessary component of a package of community-based care that promotes the autonomy of a patient. When such situations can be identified with some degree of certainty, it would be ethically defensible to use a CTO if available. This observation does not, however, legitimate the use of CTOs in general, nor does it provide a strong rationale for the introduction of these powers in jurisdictions where they are currently unavailable.

\section{Acknowledgements}


We thank our research participants for making this study possible. We also thank Anna Sulman, the research assistant who conducted some of the patient interviews. This paper summarises independent research funded by the National Institute of Health Research (NIHR) under its NIHR Programme Grant for Applied Health Research Programme (Grant Reference Number RP-PG-0606-1006). The views expressed are those of the authors and not necessarily those of the NHS, the NIHR or the Department of Health.

\section{Notes}

1. CTOs are otherwise referred to as supervised community treatment (SCT) or 'outpatient commitment'.

2. Also known as 'Ulysses Contracts' or 'Joint Crisis Plans' in Thornicroft et al. (2013).

\section{References}

Brock D. A proposal for the use of advance directives in the treatment of incompetent mentally ill persons. Bioethics 1993;7:47-56.

Burns T, Rugkåsa J, Molodynksi A, et al. Community Treatment Orders for patients with psychosis: a randomised controlled trial (OCTET). Lancet 2013;381:1627-1633.,

Canvin K, Rugkasa J, Sinclair J, Burns T. Patient, psychiatrist and family carer experiences of community treatment orders: qualitative study. Social Psychiatry and Psychiatric Epidemiology 2014; 49:1873-1872.

Care Quality Commission. Mental Health Act Annual Report 2011/12. London: CQC, 2013. 
Charmaz K. Constructing Grounded Theory. A Practical Guide through Qualitative Analysis. Thousand Oaks, CA: Sage, 2006.

Dawson J, Burns T. Community treatment orders are not a good thing: against. British Journal of Psychiatry 2008;193:96-100.

Dunn M, Maughan D, Hope T, et al. Threats and offers in community mental health care. Journal of Medical Ethics 2012;38:204-209.

Gibbs A, Dawson J, Ansley C, et al. How patients in New Zealand view community treatment orders. Journal of Mental Health 2005;14:357-368.

Glaser BG. The constant comparative method of qualitative analysis. Social Problems 1965;12:436445.

Kon A. The role of empirical research in bioethics. American Journal of Bioethics 2009;9:59-65.

Lawton-Smith S. Community treatment orders are not a good thing: for. British Journal of Psychiatry 2008;193:96-100.

Liégeois A, van Audenhove C. Ethical dilemmas in community mental health care. Journal of Medical Ethics 2005;31:452-456.

Light EM, Robertson MD, Boyce P, et al. The lived experience of involuntary community treatment: a qualitative study of mental health consumers and carers. Australasian Psychiatry 2014;22:345-351. Maughan D, Molodynski A, Rugkasa J, Burns T. A systematic review of the effect of community treatment orders on service use. Social Psychiatry and Psychiatric Epidemiology 2014;49:651-663. Munetz MR, Galon PA, Frese FJ $3^{\text {rd }}$. The ethics of mandatory community treatment. Journal of the American Academy of Psychiatry and Law 2003;31:173-183.

O'Reilly RL, Keegan DL, Corring D, et al. A qualitative analysis of the use of community treatment orders in Saskatchewan. International Journal of Law and Psychiatry 2006;29:516-524. 
Patton MQ. Qualitative evaluation and research methods. Newbury Park, CA: Sage Publications, 1990.

Rugkåsa J, Dawson J, Burns T. CTOs: what is the state of the evidence? Social Psychiatry and Psychiatric Epidemiology 2014;49:1861-1871.

Rugkåsa J, Molodynski A, Yeeles K, et al. Community treatment orders: clinical and social outcomes, and a sub-group analysis from the OCTET RCT. Acta Psychiatrica Scandinavica in press.

DOI:10.1111/acps.12373

Savulescu J, Dickenson D. The time frame of preferences, dispositions, and the validity of advance directives for the mentally ill. Philosophy, Psychiatry and Psychology 1998;5:225-246.

Snow N, Austin WJ. Community treatment orders: the ethical balancing act in community mental health. Journal of Psychiatric and Mental Health Nursing 2009;16:177-186.

Solomon MZ. Realizing bioethics' goals in practice: ten ways 'is' can help 'ought'. Hastings Center Report 2005;35:40-47.

Srebnik DS, La Fond JQ. Advance directives for mental health treatment. Psychiatric Services 1999;50:919-925.

Steadman HJ, Gounis K, Dennis D, et al. Assessing the New York City involuntary outpatient commitment pilot program. Psychiatric Services 2001;52:330-336.

Strauss AL, Corbin J. Basics of Qualitative Research. Grounded Theory Procedures and Techniques. Thousand Oaks, CA: Sage, 1990.

Stroud J, Banks L, Doughty K. Community treatment orders: learning from experiences of service users, practitioners and nearest relatives. Journal of Mental Health in press. DOI: 10.3109/09638237.2014.998809).

Swartz MS, Swanson JW, Wagner $\mathrm{H}$, et al. Can involuntary outpatient commitment reduce hospital 
recidivism? Findings from a randomised trial with severely mentally ill individuals. American Journal of Psychiatry 1999;156:1968-1975.

Thornicroft G, Farrelly S, Szmukler G, et al. Clinical outcomes of Joint Crisis Plans to reduce compulsory treatment for people with psychosis: a randomised clinical trial. Lancet 2013;381(9878):1634-1641. 
Table 1: Characteristics of the qualitative sample at time of interview

\begin{tabular}{|c|c|c|c|c|}
\hline & & $\begin{array}{l}\text { Psychiatrists } \\
\qquad \mathrm{N}=25\end{array}$ & $\begin{array}{l}\text { Patients } \\
\qquad \mathbf{N}=\mathbf{2 6}\end{array}$ & $\begin{array}{c}\text { Carers* } \\
\mathrm{N}=24 \\
\text { (Patients Cared } \\
\text { for } \mathrm{N}=21 \text { ) }\end{array}$ \\
\hline & Male & 19 & 18 & 7 \\
\hline \multirow[t]{3}{*}{ Ethnicity } & White & 18 & 14 & 21 \\
\hline & Black & - & 7 & 0 \\
\hline & Others & - & 5 & 3 \\
\hline \multirow[t]{7}{*}{ Geographical location } & North West & - & - & 3 \\
\hline & South West & 2 & 1 & 4 \\
\hline & South East & 10 & 7 & 8 \\
\hline & East & 2 & 1 & 1 \\
\hline & East Midlands & 2 & 1 & 1 \\
\hline & West Midlands & 5 & 8 & 2 \\
\hline & London & 4 & 8 & 3 \\
\hline Primary diagnosis & Schizophrenia & - & 18 & (21) \\
\hline \multirow[t]{4}{*}{ (/of cared for) } & Bipolar & - & 7 & (3) \\
\hline & Other psychosis & - & 1 & (0) \\
\hline & Depot & - & 14 & (11) \\
\hline & History of violence & - & - & (12) \\
\hline \multirow[t]{2}{*}{ Team } & $\mathrm{CMHT}$ & 6 & 11 & $(-)$ \\
\hline & AOT & 6 & 9 & $(-)$ \\
\hline
\end{tabular}




\begin{tabular}{|c|c|c|c|c|}
\hline & EIS & 2 & 1 & $(-)$ \\
\hline & Forensic & 1 & 0 & $(-)$ \\
\hline & Unknown/not specified & 0 & 5 & (21) \\
\hline \multirow[t]{5}{*}{ Setting/role } & Inpatient & 7 & - & - \\
\hline & Community & 14 & - & - \\
\hline & Inpatient/community & 4 & - & - \\
\hline & SOAD & 1 & - & - \\
\hline & $\begin{array}{l}\text { Recruited for OCTET study (Burns et } \\
\text { al., 2013) }\end{array}$ & 19 & - & - \\
\hline \multirow[t]{5}{*}{ СТO use } & & 2 & - & - \\
\hline & 0 & 11 & - & - \\
\hline & $0-10$ & 4 & - & - \\
\hline & $10-20$ & 8 & - & - \\
\hline & $20+$ & & & \\
\hline \multirow{3}{*}{$\begin{array}{l}\text { Relationship to cared } \\
\text { for }\end{array}$} & Parent & - & - & 22 \\
\hline & Spouse & - & - & 1 \\
\hline & Sibling & - & - & 1 \\
\hline CTO status & Ongoing СTO & - & 13 & (14) \\
\hline \multirow[t]{4}{*}{ at interview } & Revoked & - & 4 & (2) \\
\hline & Ended for unknown reason & - & 8 & (0) \\
\hline & Discharged & - & - & (3) \\
\hline & Interviewee unsure & - & - & (2) \\
\hline \multirow[t]{5}{*}{ Duration } & $<6$ months & - & 15 & (1) \\
\hline & 6-12 months (renewed once) & - & 8 & (9) \\
\hline & $12+$ months (renewed twice or more) & - & 2 & (8) \\
\hline & Interviewee unsure & - & - & (3) \\
\hline & Experience of recall & - & 7 & (8) \\
\hline
\end{tabular}


